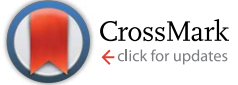

Cite this: J. Mater. Chem. A, 2014, 2 , 20996

Received 12th September 2014 Accepted 28th October 2014

DOI: $10.1039 / c 4 t a 04787 g$

www.rsc.org/MaterialsA

\section{Highly porous flame-retardant and sustainable biofoams based on wheat gluten and in situ polymerized silica $\uparrow$}

\author{
Qiong Wu, ${ }^{a}$ Richard L. Andersson, ${ }^{a}$ Tim Holgate, ${ }^{b}$ Eva Johansson, ${ }^{c}$ Ulf W. Gedde, ${ }^{a}$ \\ Richard T. Olsson ${ }^{a}$ and Mikael S. Hedenqvist ${ }^{\star a}$
}

\begin{abstract}
This article presents a novel type of flame-retardant biohybrid foam with good insulation properties based on wheat gluten and silica, the latter polymerized in situ from hydrolysed tetraethyl orthosilicate (TEOS). This led to the formation of intimately mixed wheat gluten and silica phases, where, according to protein solubility measurements and infrared spectroscopy, the presence of silica had prohibited full aggregation of the proteins. The foams with "built-in" flame-retardant properties had thermal insulation properties similar to those of common petroleum- and mineral-based insulation materials. The foams, with a porosity of 87 to $91 \%$, were obtained by freeze-drying the liquid mixture. Their internal structure consisted of mainly open cells between 2 and $144 \mu \mathrm{m}$ in diameter depending on the foam formulation, as revealed by mercury intrusion porosimetry and scanning electron microscopy. The foams prepared with $\geq 30 \%$ TEOS showed excellent fire-retardant properties and fulfilled the criteria of the best class according to UL94 fire testing standard. With increasing silica content, the foams became more brittle, which was prevented by cross-linking the materials (using gluteraldehyde) in combination with a vacuum treatment to remove the largest air bubbles. X-ray photoelectron and infrared spectroscopy showed that silicon was present mainly as $\mathrm{SiO}_{2}$.
\end{abstract}

\section{Introduction}

A great challenge is to obtain environment-friendly biofoams that show a combination of good insulating and fire-resistant properties. Polymeric foams are commonly used in applications such as packaging, thermal and sound insulation, buoyancy and other fields where porous and lightweight structures are required. Polymeric foams are almost exclusively petroleumbased and burn with high flammability generating toxic gases and little or no residual char. The formation of a low-viscous tar that drips and may cause secondary fires is also problematic and often observed during their burning. ${ }^{1}$ These foams therefore require flame-retardants, which, in turn, make them difficult to dispose of and to recycle. ${ }^{2}$ The most common polyurethanes also compromise human safety due to the frequent utilization of cyanide-based chemicals. ${ }^{3}$ Non-flammable biofoams are therefore of great interest. To be of viable

${ }^{a}$ Department of Fibre and Polymer Technology, School of Chemical Science and Engineering, KTH Royal Institute of Technology, SE-10044, Stockholm, Sweden

${ }^{b}$ Department of Energy Conversion and Storage, Technical University of Denmark, DK4000, Roskilde, Denmark

${ }^{c}$ Department of Plant Breeding, The Swedish University of Agricultural Sciences, Alnarp, SE-23053, Sweden

$\dagger$ Electronic supplementary information (ESI) available. See DOI: $10.1039 / \mathrm{c} 4 \mathrm{ta} 04787 \mathrm{~g}$ relevance, these alternative materials should be of porosities $>90 \%$ to meet with the insulation characteristics of traditional polymeric foams. ${ }^{4}$

For a sustainable reason, there is a strong motivation to develop new foam-materials based on renewable resources obtained from large-scale forestry or agricultural feedstock. Of particular interest are the polysaccharides (e.g. cellulose, starch, alginates, pectin, carrageenan, chitosan/chitin) and proteins Among these, one of the more interesting alternative is the wheat gluten (WG), which is a major co-product in ethanolbiofuel production. ${ }^{6}$ After fermentation and conversion of starch into ethanol, the gluten is obtained in adequate quantities with uniform and good quality at a comparatively low price (1 \$ per kg). ${ }^{7}$ One of the most interesting characteristics of the WG protein is its viscoelastic and good foaming properties, ${ }^{\mathbf{8 , 9}}$ in combination with its ability to form disulphide crosslinks between the protein molecules. ${ }^{\mathbf{1 0}}$ These features allow the preparation of WG foams from aqueous solutions of the proteins by freeze-drying the WG suspensions., ${ }^{711-14}$ The thermal conductivity of the WG foams with a density of $130 \mathrm{~kg} \mathrm{~m}^{-3}$ is similar to that of glass wool, making them interesting as insulation materials. ${ }^{\mathbf{1 1}}$ In addition, the foams can be used as adsorbents/sponges.

Whereas several studies deal with the mechanical properties of bio-based polymeric foams, their fire properties have received (e.g. casein, whey, collagen, gelatine, corn, soy, wheat gluten). ${ }^{5}$ 
almost no attention. ${ }^{15}$ This is unfortunate since any implementation of the environment-friendly biofoam alternatives (on the realm of their petroleum-based counterparts) ultimately relies on the combination of adequate insulation capacity, mechanical properties and flame retardant characteristics. The aim of this study was therefore to prepare WG foams with flameretardant properties using a new approach where the wheat gluten was foamed together with silica. The latter was prepared from tetraethyl orthosilicate (TEOS) using catalytic sol-gel chemistry to form the silica in situ during the foam preparation. The results show that the silica modified wheat-gluten foams fulfil the criteria of the best "fire-proof" classification, according to the UL94 fire testing protocol for vertical burning testing. The foam structure was characterized by scanning electron microscopy and mercury intrusion porosimetry, which revealed that internal foam structures could be controlled by allowing ice crystals to shape the cellular structure of the foams. A rapid freezing allowed almost one order of magnitude smaller cell sizes. The silica and protein chemistry was revealed by X-ray photoemission spectroscopy (XPS), infrared spectroscopy (IR) and size-exclusion high performance liquid chromatography (HPHC). Compression tests showed that increasing silica content resulted in more brittle foams, which could be compensated for by introducing glutaraldehyde (GA) (working as a 'cross-linker' of the protein). The thermal conductivity of the novel foams was shown to be similar to that of common petroleum- and mineral-based foams.

\section{Experimental}

\subsection{Wheat gluten}

Lantmannen Reppe AB, Sweden, supplied wheat gluten powder. The wheat gluten protein content was $77.7 \mathrm{wt} \%$ (modified NMKL Nr 6, Kjeltec, Nx5.7) and the starch content was $5.8 \mathrm{wt} \%$, as determined by the Ewers polarimetric method. The lipid content was $1.2 \mathrm{wt} \%$ of the dry weight (Soxtec, Lidfett.OA.19, tecator AN 301).

\subsection{Biohybrid foam preparation}

A silica-based aqueous ethanol solution of tetraethyl orthosilicate (TEOS, Sigma Aldrich, reagent grade 98\%) was prepared by mixing $10 \mathrm{~g}$ of TEOS with $4.9 \mathrm{~g}$ of a $40 \mathrm{vol} \%$ solution of ethanol in Milli-Q water. The molar ratio of $\mathrm{H}_{2} \mathrm{O}$ : TEOS was $4: 1$. As a catalyst, $0.12 \mathrm{~g}$ of $1 \mathrm{M} \mathrm{HCl}$ was added to the TEOS solution (final solution $\mathrm{pH}=2.0 \pm 0.8) .{ }^{16}$ The solution was stirred at room temperature for $c a .1 \mathrm{~h}$ to complete the hydrolysis of TEOS (silica precursor), which was delayed due to the presence of the ethanol. After $1 \mathrm{~h}$, the dissolved silica precursor solution had become a completely transparent and clear, showing no signs of phase separation.

During the preparation of the TEOS solution, $10 \mathrm{~g}$ of wheat gluten was dispersed separately in $100 \mathrm{~mL}$ Milli-Q water using a Philips Chopper mixer (model HR 1392). The pH of the wheat gluten dispersion was adjusted to 11 with $1 \mathrm{M} \mathrm{NaOH}$ (Sigma Aldrich, puriss, p.a. ACS $>98 \%$ ). After stirring the wheat gluten aqueous dispersion for $c a .10 \mathrm{~min}$, the total amount of the dispersion was increased to $120 \mathrm{~mL}$ by adding Milli-Q water. The dispersion was then transferred to a glass beaker and heated in an oil bath to $90{ }^{\circ} \mathrm{C}$, at an average heating rate of approximately $7{ }^{\circ} \mathrm{C} \mathrm{min}^{-1}$, to provide suitable conditions for denaturation. After reaching $90{ }^{\circ} \mathrm{C}$, the mixture was rapidly cooled to room temperature. Subsequently, the wheat gluten dispersion was foamed to a volume of $300 \%$ relative to the initial volume, using a Yellow Line Di 25 basic homogenizer from IKA, equipped with a S25N-18G dispersion tool. The final dispersion was obtained by dropwise addition of the TEOS solution (hydrolysed for $1 \mathrm{~h}$ ) to the WG dispersion that was homogenized for $10 \mathrm{~min}$ at $9500 \mathrm{rpm}$, allowing uniform mixing of the silica precursor phase. The above preparation route refers to the $50 \mathrm{wt} \%$ TEOS containing WG foam.

The amounts of TEOS added were: 5, 10, 20, 30, 40, 50 and $80 \mathrm{wt} \%$ relative to the total solids content (WG + TEOS). The relative ratios of the chemicals used for the hydrolysed TEOS solution remained constant.

The mixture was poured into cuboid-shaped silicone moulds with dimensions of $10 \times 10 \times 11(\mathrm{~mm})^{3}$ and $125 \times 13 \times 10$ $(\mathrm{mm})^{3}$. The smaller mould size was used to make foams for most analysis, except for the UL94 fire testing, which required specimens obtained from the larger mould. In addition, cylinder-shaped moulds with a diameter of $25 \mathrm{~mm}$ and a height of $12 \mathrm{~mm}$ were used to make foams for compression testing. The moulds containing the mixture were frozen in liquid nitrogen $\left(-196{ }^{\circ} \mathrm{C}\right)$ for $\mathrm{ca} .3 \mathrm{~min}$ or in a cold room $\left(-25{ }^{\circ} \mathrm{C}\right)$ for $12 \mathrm{~h}$ before being freeze-dried for $24 \mathrm{~h}(48 \mathrm{~h}$ for the $125 \times 13 \times$ $10(\mathrm{~mm})^{3}$ samples). All the moulds were pre-cooled in liquid nitrogen or in the cold room before use.

The foam samples were identified by the TEOS content used. Assuming complete conversion, the samples produced with TEOS contents of 5, 10, 20, 30, 40, 50 and $80 \mathrm{wt} \%$ corresponded to silica contents of $1.5,3.1,6.7,11.0,16.1,22.4$ and $53.6 \mathrm{wt} \%$ respectively, on complete transformation of the TEOS into silica.

The samples frozen in liquid $\mathrm{N}_{2}$ and in the cold room were named WG with the TEOS content followed by the freezing temperature; e.g. samples prepared with $50 \mathrm{wt} \%$ TEOS and frozen in liquid $\mathrm{N}_{2}\left(-196{ }^{\circ} \mathrm{C}\right)$ or in the cold room $\left(-25{ }^{\circ} \mathrm{C}\right)$ were named, WG/50TEOS/-196 and WG/50TEOS/-25, respectively.

Some foams were cross-linked with glutaraldehyde (GA, Sigma Aldrich, $50 \mathrm{wt} \%$ solution in water). For this purpose, 8 or $16 \mathrm{wt} \%$ (relative to the WG content) of GA was added to the homogenized and denatured WG dispersion. $10 \mathrm{~min}$ of additional homogenization was used to disperse the GA. In some cases, the WG/TEOS mixture was put in a vacuum oven (300 mbar) for $c a .15 \mathrm{~min}$ at room temperature in order to remove the largest cells originating from trapped air during the homogenization/mixing stage. The pressure was cycled between 1 bar and 300 mbar in order to avoid a rapid and uncontrolled rise of the mixture in the beaker. This led to a reduction in foam volume by $c a$. $10 \%$. The samples with GA were identified with WG followed by the TEOS content, GA content, and the cooling condition, e.g. WG/30TEOS/8GA/-25. Note that here after, for 
simplicity, per cent values (\%) of TEOS, silica and GA refer to wt $\%$.

\subsection{Field-emission scanning electron microscopy (FE-SEM)}

The morphology of the samples was revealed using a Hitachi S-4800 field-emission scanning electron microscope (FE-SEM). The specimens were prepared by making a small V-notch on one of the cuboidal foam faces before it was frozen in liquid nitrogen for $20 \mathrm{~min}$. The foam was removed from the liquid nitrogen and fractured by bending it with a set of tweezers that had been precooled in liquid nitrogen. The specimens were then carefully fixed on aluminium specimen holders using carbon paste, and dried in a vacuum oven ( $c a .300 \mathrm{mbar}$ ) at room temperature for $3 \mathrm{~h}$. Before examination in the microscope, the specimens were coated with platinum/palladium (60/40) for $120 \mathrm{~s}$, using a Cressington high resolution sputter coater (model 208RH). In order to see the silica structure after removal of the WG component, taken from the mixture just before the freezing in the freeze-drying operation, the mixture was centrifuged in a Rotina 420 three times at $25{ }^{\circ} \mathrm{C}$ and 188 $\mathrm{RCF}$ for a total time of $30 \mathrm{~min}$. Between the centrifuging operations, the supernatant was decanted and replaced with $40 \mathrm{~mL}$ Milli-Q water, followed by shaking until the suspension became homogeneous. After the centrifugation, the precipitate was collected and dried in an oven at $80{ }^{\circ} \mathrm{C}$ for $48 \mathrm{~h}$.

\subsection{Mercury intrusion porosimetry (MIP)}

All samples were dried in a desiccator with silica gel for at least $48 \mathrm{~h}$ before they were measured in an AutoPoreIV 9510 V1.06 porosimeter. A piece of sample cut from the central part of the small cuboid-shaped specimen was placed in a glass tube, which was subsequently filled with mercury under low-pressure (less than 0.7 Bar). The evacuation lasted for $5 \mathrm{~min}$, and after filling with mercury, equilibration for $10 \mathrm{~s}$ followed. The glass tube was transferred into a high-pressure analysis chamber where oil was used to force the mercury into the specimen with a stepwise pressure increase from 0.7 to 410 Bar. The cell size was calculated based on the assumption that the cells had a circular channel-shape with open ends. ${ }^{17}$

\subsection{Thermal diffusivity by laser flash analysis (LFA) and heat capacity by differential scanning calorimetry (DSC)}

The thermal diffusivity was determined using the laser flash technique (LFA457, Netzsch, Germany). 1.5 to $4 \mathrm{~mm}$ thick crosssections of the small cuboidal samples were taken and affixed between two aluminium plates, each ca. $0.4 \mathrm{~mm}$ thick, using a thin layer of thermally conducting silver paste. Care was taken to use only enough paste to achieve full contact throughout the cross-section while attempting to limit the flow of the paste into open pores of the foam. In order to obtain a statistical estimate of the uncertainty, five measurements were made at each temperature, and at least two samples of each material were used to validate the reproducibility of the measurements to be assessed. The diffusivity was calculated from the raw data using the "three-layer with heat loss + pulse correction" model provided in the LFA Analysis software (ver. 6.0, Netzsch). This model takes into account the half-time of the temperature versus time profile of the surface of the sample opposite to the side receiving the laser pulse. The three-layer model interpolates between expected signal profiles calculated using data provided for the aluminium plates. The resulting half-time $\left(t_{0.5}\right)$ and the thickness $(d)$ of the foam layer were then fed into the standard Cowan model: ${ }^{18}$

$$
D=0.1388 d^{2} / t_{0.5}
$$

The specific heat capacity $\left(C_{\mathrm{p}}\right)$ was measured using a Mettler Toledo DSC 1 in a nitrogen atmosphere (gas flow rate $=50 \mathrm{~mL}$ $\min ^{-1}$ ). Two $100 \mu \mathrm{L}$ aluminium pans, one empty and one with $13 \pm 1 \mathrm{mg}$ sample, were used. Both pans were first heated from $25{ }^{\circ} \mathrm{C}$ to $120{ }^{\circ} \mathrm{C}$ at a heating rate of $10{ }^{\circ} \mathrm{C} \mathrm{min}{ }^{-1}$, and kept at $120^{\circ} \mathrm{C}$ for $5 \mathrm{~min}$. After being cooled to $25^{\circ} \mathrm{C}$ at a cooling rate of $10{ }^{\circ} \mathrm{C} \mathrm{min}{ }^{-1}$, they were then heated a second time from $25^{\circ} \mathrm{C}$ to $80{ }^{\circ} \mathrm{C}$ at a heating rate of $1{ }^{\circ} \mathrm{C} \mathrm{min}^{-1}$. The reason for using the second heating to determine $C_{\mathrm{p}}$ was to avoid further denaturation of proteins, which occurred during the first heating process. The specific heat capacity was calculated according to: ${ }^{19}$

$$
C_{\mathrm{p}}=\Delta Q /(m v)
$$

where $\Delta Q$ is the difference in heat flux between the pan with sample and the empty pan, $m$ is the weight of the sample and $v$ is the heating rate. The thermal conductivity $(\lambda)$ was obtained as: ${ }^{19}$

$$
\lambda=D C_{\mathrm{p}} \rho
$$

\subsection{UL94 vertical burning test}

The UL94 vertical burning test was used to characterize the flammability properties of the samples. Before testing, the specimens were conditioned at $23 \pm 1{ }^{\circ} \mathrm{C}$ and $50 \pm 2 \%$ relative humidity for at least $48 \mathrm{~h}$. Each specimen was fixed vertically ca. $300 \mathrm{~mm}$ above a cotton layer. The cotton was conditioned in a desiccator containing silica gel for at least $24 \mathrm{~h}$ prior to use. The burner with flame (ca. $20 \mathrm{~mm}$ high) was applied vertically at the bottom of the specimen for $10 \mathrm{~s}$, and then, if the flame selfextinguished, the burner was applied again for $10 \mathrm{~s}$. For each material, five specimens were tested. The flammability data (e.g. after-flame time after each $10 \mathrm{~s}$ burning) was compared with the UL94 criteria for the classifications: V-0, V-1 and V-2 (see Table S1, ESI $\dagger$ ). To compare the flammability of wheat gluten/silica foams with commercial polyurethane foams, a comparable fire test was complemented with thermographic imaging using a FLIR E-30 infrared camera (FLIR Systems, USA) at intermediate time steps during the UL94 characterization. The images were taken when two foam specimens were simultaneously ignited, a WG-based foam (WG/30TEOS/8GA/-25) and a polyurethane foam of similar density $\left(150 \mathrm{~kg} \mathrm{~m}^{-3}, \mathrm{PUR}\right.$, http://www.kinn.com, Sweden). 


\subsection{Thermogravimetric analysis (TGA)}

Thermogravimetric analysis was carried out using a MettlerToledo TGA/DSC $1 \mathrm{LF} / 905$. WG and WG-based hybrid foams (ca. $7 \mathrm{mg}$ ) were placed in alumina pans $(70 \mu \mathrm{m})$, heated from $30{ }^{\circ} \mathrm{C}$ to $100{ }^{\circ} \mathrm{C}$ at a heating rate of $10{ }^{\circ} \mathrm{C} \mathrm{min}$ m $^{-1}$ in $\mathrm{O}_{2}$ atmosphere with a gas flow of $50 \mathrm{~L} \mathrm{~min}^{-1}$. Then the temperature was kept at $100{ }^{\circ} \mathrm{C}$ for $20 \mathrm{~min}$ in order to eliminate adsorbed moisture in the foams. The foams were then heated to $900{ }^{\circ} \mathrm{C}$ at a heating rate of $10^{\circ} \mathrm{C} \mathrm{min}^{-1}$.

\subsection{Infrared (IR) spectroscopy}

IR spectra based on 16 scans were recorded using a Spectrum 2000 FTIR spectrometer (Perkin-Elmer inc., USA). The spectrometer was equipped with a single reflection ATR accessory, golden gate from Specac Ltd. All the samples were dried in a desiccator over silica gel for several weeks before analysis.

\subsection{X-ray photoelectron spectroscopy (XPS)}

The top 2-10 nm surfaces of a WG and a WG/30TEOS/-25 foam (before and after burning) were analysed using a Kratos AXIS UltraDLD X-ray photoelectron spectrometer (Kratos Analytical, Manchester, UK). The samples were analysed using a monochromatic $\mathrm{Al} \mathrm{K} \alpha \mathrm{X}$-ray source. The analysis area was typically less than ca. $0.2 \mu \mathrm{m}^{2}$.

\subsection{Compression test}

Compression testing was performed on cylindrical samples using an Instron 5566 universal testing machine with a $500 \mathrm{~N}$ load cell. Instron compression plates (T1223-1021), with a diameter of $50 \mathrm{~mm}$, were used in accordance with ISO 844:2007 for rigid foams. Before the tests, all the specimens were conditioned at $23 \pm 1{ }^{\circ} \mathrm{C}$ and $50 \pm 2 \% \mathrm{RH}$ for a minimum of $120 \mathrm{~h}$. The compression rate was $10 \% \mathrm{~min}^{-1}$ of the original specimen thickness and the final compressive strain was $80 \%$. For each sample, 5 specimens were tested.

\subsection{Size-exclusion high-performance liquid chromatography (SE-HPLC)}

The protein solubility of the foams was assessed by size-exclusion high-performance liquid chromatography (SE-HPLC), using sodium dodecyl sulphate (SDS) as a solvent in combination with ultrasonication following the three-step extraction procedure described in Gallstedt et al. ${ }^{13}$ In the first extraction (Ext. 1), $16.5 \pm 0.05 \mathrm{mg}$ of each foam was suspended in $1.4 \mathrm{~mL}$ of $0.5 \%$ SDS-phosphate buffer $(\mathrm{pH}=6.9)$ and vortexed for $5 \mathrm{~s}$. The suspension was then stirred for $5 \mathrm{~min}$ at $2000 \mathrm{rpm}$ and centrifuged at $8160 \mathrm{G}$ for $30 \mathrm{~min}$ to obtain the supernatant SDSsoluble protein. In the second extraction (Ext. 2), the pellet was re-suspended in a new SDS buffer and then sonicated in an ultrasonic disintegrator (Soniprep 150, Tamro) for $30 \mathrm{~s}$, amplitude 5 , fitted with a $3 \mathrm{~mm}$ exponential microtip. The samples were then centrifuged for $30 \mathrm{~min}$ to obtain a supernatant of proteins. In the third extraction (Ext. 3), the pellet was re-suspended in a new SDS buffer and sonicated as above for $30+60$ $\mathrm{s.}^{20}$ An in-line filter system was used for the SE-HPLC analysis performed on a Waters HPLC system using a BIOSEP SEC-4000 Phenomenex column. Separation was obtained during $30 \mathrm{~min}$ by loading $20 \mu \mathrm{L}$ of sample into an eluant of $50 \mathrm{vol} \%$ acetonitrile and water containing 0.1 vol\% trifluoroacetic acid at a flow rate of $0.2 \mathrm{~mL} \mathrm{~min}^{-1}$. The proteins were detected by a DAD detector, and the absorption chromatograms were obtained at $210 \mathrm{~nm}$. Six replicates from two different batches were used. To evaluate the total amount of proteins extracted from the samples, the nitrogen content in the residual material after the three extractions was determined. After lyophilisation, the mass of the whole residual sample was determined and the nitrogen content was obtained using the Dumas method according to Newson et al. ${ }^{21}$ in an Elemental Analyzer (Flash 2000, Thermo Scientific). Acetanilide was used as a standard. The protein content was determined using 5.7 as the conversion factor. Considering the fairly large amount of unextracted protein after the three-step extraction ( $c a .30 \mathrm{wt} \%$ ), the protein solubility/ amount of extracted material after the three-step extractions of the pristine wheat gluten foam was used as reference. The protein solubility of the other samples was normalized with respect to the solubility value of pristine wheat gluten.

\subsection{Moisture content}

Small cuboidal foams were dried in a desiccator over silica gel at room temperature for at least 2 weeks. The sample mass was determined and the samples were then transferred to a climate room at $23 \pm 1{ }^{\circ} \mathrm{C}$ and $50 \pm 2 \% \mathrm{RH}$. After at least one month, the sample mass was recorded and the moisture content was obtained as the mass increase divided by the dry sample mass.

\section{Results and discussion}

\subsection{Flammability properties and the burning process}

Fig. 1(a-c) displays simultaneously taken thermographic and photographic images of a silica modified wheat gluten foam and a polyurethane (PUR) foam during the burning test. The images were taken before exposure to the flame, at $3 \mathrm{~s}$ after, and at $15 \mathrm{~s}$ after removing the external flame. The images present one of the best performing silica modified WG foams in terms of apparent burning behaviour (as compared to a stiff polyurethane foam). This WG/30TEOS/8GA/-25 foam was prepared with $30 \%$ TEOS to give an internal silica structure and $8 \%$ GA to crosslink the proteins, before freezing at $-25{ }^{\circ} \mathrm{C}$ (see complete sample overview in Table 1).

The PUR sample instantaneously caught fire as it was exposed to the $c a .2000{ }^{\circ} \mathrm{C}$ flame from the propane driven burner unit, whereas the WG/30TEOS/8GA/-25 foam required more than $3 \mathrm{~s}$ inside the flame before an apparent flame from the silica modified WG foam could be observed.

The thermographic images further revealed a completely different time-dependant temperature profile for the two samples following the ignition. The maximum surface temperature of the silica modified WG foam and the PUR foam $3 \mathrm{~s}$ after removal of the external propane flame were 335 and $400{ }^{\circ} \mathrm{C}$, respectively (Fig. 1b). The PUR foam maintained a surface temperature that exceeded the auto-ignition point of paper 
(a)

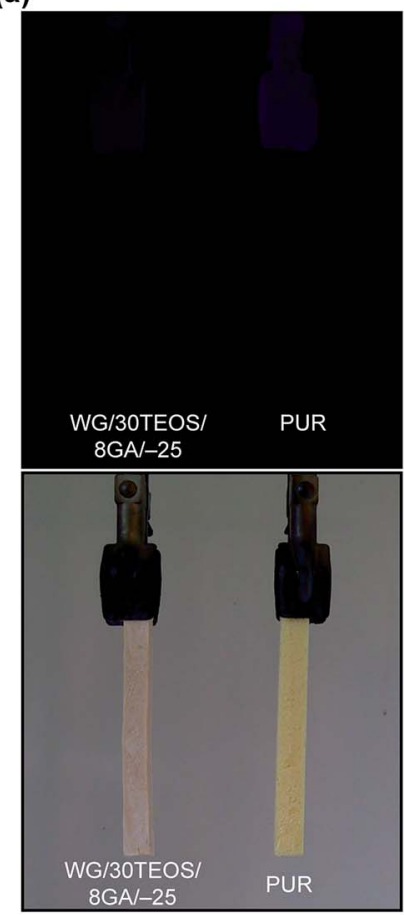

Before exposure to flame (b)

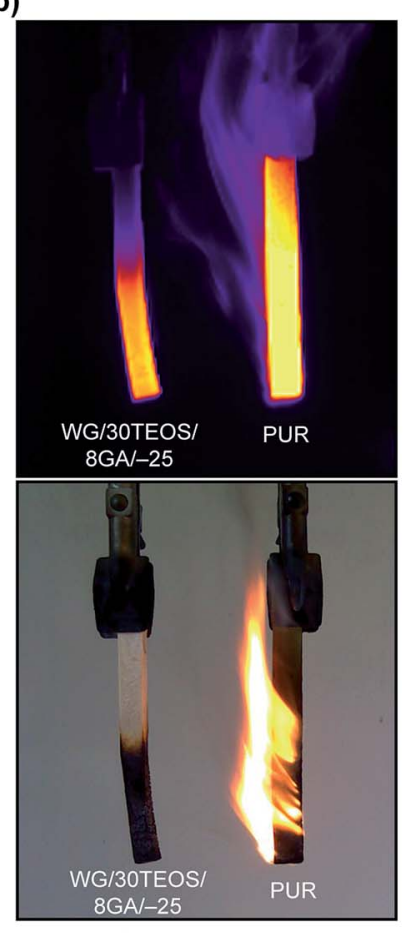

$3 \mathrm{~s}$ after flame removal (c)

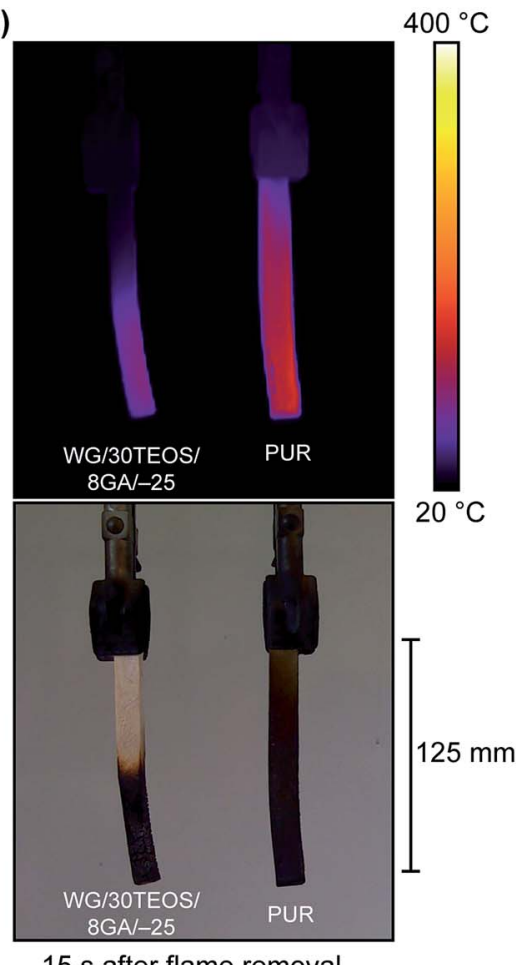

$15 \mathrm{~s}$ after flame removal

Fig. 1 Thermographic images (top) of the WG/30TEOS/8GA/-25 and polyurethane (PUR) foams during the burning test at different times (a: before, b: $3 \mathrm{~s}$ and $\mathrm{c}$ : $15 \mathrm{~s}$ after flame removal) and photographs (bottom) taken at exactly the same times.

$\left(233^{\circ} \mathrm{C}\right)^{22}$ for $8 \mathrm{~s}$ after removal of the external flame. At this time, the WG/30TEOS/8GA/-25 sample had a maximum surface temperature of only $156^{\circ} \mathrm{C}$. The WG/30TEOS/8GA/-25 foam self-extinguished after 1-2 $\mathrm{s}$, whereas the PUR sample continued to burn for $\geq 8 \mathrm{~s}$. In Fig. 1c, $15 \mathrm{~s}$ after removal of the external flame, the temperature had decreased to $104{ }^{\circ} \mathrm{C}(\mathrm{WG} /$ 30TEOS/8GA/-25) and $158{ }^{\circ} \mathrm{C}$ (PUR). Nearly the entire PUR- foam had been converted into black char at this stage, (Fig. 1c, bottom), whereas only half of the silica modified WG-foam showed char and the rest was visibly intact. The reason for the observed difference and smaller heat release for the silica modified WG foam was at this stage unclear, but the heat release at the different stages clearly show that a higher surface temperature was reached for the PUR foam, which was taken as

Table 1 Specifications of the foam samples' composition, freezing conditions, densities and UL94 classification

\begin{tabular}{|c|c|c|c|c|c|c|c|c|c|}
\hline Sample ID & $\begin{array}{l}\text { WG } \\
(w t \%)\end{array}$ & $\begin{array}{l}\text { TEOS } \\
(\mathrm{wt} \%) \\
\end{array}$ & $\begin{array}{l}\text { GA } \\
(\mathrm{wt} \%)^{a}\end{array}$ & $\begin{array}{l}\text { Freezing } \\
\text { condition }\left({ }^{\circ} \mathrm{C}\right)\end{array}$ & $\begin{array}{l}\text { Cell size } \\
(\mu \mathrm{m})_{\text {SEM }}\end{array}$ & $\begin{array}{l}\text { Density } \\
\left(\mathrm{kg} \mathrm{m}^{-3}\right)\end{array}$ & $\begin{array}{l}\text { UL94 } \\
\text { classification }\end{array}$ & $\mathrm{SET}_{1}(\mathrm{~s})$ & $\mathrm{SET}_{2}(\mathrm{~s})$ \\
\hline WG/-25 & 100 & 0 & 0 & -25 & 49 & $130.4 \pm 7.6$ & Fail & $>68.6^{b}$ & N/A \\
\hline WG/20TEOS/-25 & 80 & 20 & 0 & -25 & 44 & $162.6 \pm 2.5$ & Fail & 32.6 & 17.6 \\
\hline WG/30TEOS/-25 & 70 & 30 & 0 & -25 & 65 & $151.1 \pm 4.6$ & V-0 & 0 & 1.2 \\
\hline WG/40TEOS/-25 & 60 & 40 & 0 & -25 & 58 & $157.4 \pm 2.0$ & $\mathrm{~V}-0$ & 0.2 & 0.2 \\
\hline WG/5TEOS/-196 & 95 & 5 & 0 & -196 & 5 & $165.9 \pm 10.0$ & - & - & - \\
\hline WG/20TEOS/-196 & 80 & 20 & 0 & -196 & 6 & $133.7 \pm 2.4$ & V-0 & 3 & 1.7 \\
\hline WG/30TEOS/-196 & 70 & 30 & 0 & -196 & 5 & $141.0 \pm 4.2$ & $\mathrm{~V}-0$ & 0.2 & 0.4 \\
\hline WG/40TEOS/-196 & 60 & 40 & 0 & -196 & 4 & $157.8 \pm 7.1$ & - & - & - \\
\hline WG/50TEOS/-196 & 50 & 50 & 0 & -196 & 6 & $127.0 \pm 3.6$ & - & - & - \\
\hline WG/20TEOS/8GA/-25 & 74 & 20 & 6 & -25 & 85 & $146.2 \pm 3.9$ & $\mathrm{~V}-0$ & 0.2 & 0.4 \\
\hline
\end{tabular}

${ }^{a}$ GA content relative to the WG content. Fail = did not meet any classification within the standard/burned readily. ${ }^{b}$ The full samples burned up till

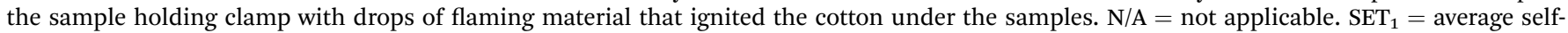
extinguished time after first $10 \mathrm{~s}$ application of the burner. $\mathrm{SET}_{2}=$ average self-extinguished time after second $10 \mathrm{~s}$ application of the burner. 
an indication that more material was consumed during the exothermic degradation. Table 1 shows the composition and freezing conditions of all the foams prepared with different contents of TEOS, and in some cases a crosslinking agent (GA).

The influence of the TEOS content was first investigated for the foams without cross-linker. The samples frozen at $-25{ }^{\circ} \mathrm{C}$ prepared with 50, 40 and 30\% TEOS showed very good flameretardant properties and fulfilled the criteria for the best UL94 class (V-0, Table S2, ESI $\dagger$ ). To fulfil this classification, the total after-flame time after two consecutive $10 \mathrm{~s}$ applications of the burner on 5 replicates, had to be equal to or less than $50 \mathrm{~s}$.

The 50, 40 and $30 \%$ TEOS samples frozen at $-25{ }^{\circ} \mathrm{C}$ were difficult to ignite, and immediately self-extinguished after removal of flame. The total after-flame time was $\leq 5 \mathrm{~s}$ for all these foams (4, 2 and 5 s respectively). In addition, no dripping of flaming material was observed and the cotton placed under the sample was not ignited. Whereas the samples with a TEOS content $\geq 30 \%$ showed a unique ability to self-extinguish, the samples prepared with $20 \%$ TEOS, or less, did not qualify in any of the UL94 classes and burned readily up to the sample holding clamp. The total after-flame times increased with decreasing TEOS contents, and were always longer than $250 \mathrm{~s}$ (Table S2, ESI $\dagger$ ). These materials also generated drops of flaming material that ignited the cotton under the samples. For comparison, the pure WG foam had an after-flame time of $343 \mathrm{~s}$.

To investigate if the cell size had an impact on the fireresistance, the 30 and $20 \%$ TEOS foams were prepared by freezing them in liquid $\mathrm{N}_{2}\left(-196^{\circ} \mathrm{C}\right)$, resulting in ca. 10 times smaller cells for the freeze dried foams (Table 1 and Section 3.3, Fig. 4 and 5). Both the 30 and $20 \%$ foams fulfilled the V-0 classification. However, the transition between the 30 and $20 \%$ foams was still evident and the total after-flame time was significantly longer for the foam with $20 \%$ TEOS (23 s) as compared to the foam with $30 \%$ TEOS, which self-extinguished with an after-flame time of $3 \mathrm{~s}$. It was therefore concluded that a transition in flammability existed for the materials with TEOS content between 20 and $30 \%$, and that a smaller cell size contributed to improved fire resistance. The last three columns to the right in Table 1 shows the outcome of all the performed tests according to the UL94 standard.

For mechanical-property reasons, dealt with later in this paper, additional foams were prepared with 30 and 20\% TEOS using $8 \%$ GA to crosslink the protein chains. The foams were frozen at $-25{ }^{\circ} \mathrm{C}$. The addition of GA resulted in foams with $c a$. double cell size compared to the foams prepared under identical conditions without the cross-linker. The fire testing revealed that the crosslinking had a significant effect on the flammability of the sample with $20 \%$ TEOS, which self-extinguished with a total after-flame time of $3 \mathrm{~s}$ (compare $23 \mathrm{~s}$ for the small-sized $20 \%$ TEOS foam and $250 \mathrm{~s}$ for the $20 \%$ TEOS foam without cross-linked protein molecules). A cross-linked foam using only $10 \%$ TEOS was therefore tested. This foam failed the V-0 classification but attained the second best (V-1) class at an after-flame time of $145 \mathrm{~s}$. Accordingly, the crosslinking, which also resulted in a stronger material (see Section 3.4), evidently provided a strong flame-retardancy to the foams. However, it was difficult to prepare uniform foams from the mixture with
$10 \%$ TEOS in combination with GA. The relatively high content of WG in combination with the GA extensively cross-linked the protein molecules to an extent where the viscosity became exceedingly high to flow into the mould cavity used for preparing the foams. Hence that sample was not exploited further and was therefore not included in Table 1.

\subsection{Post-burning characterization and structure of residual material}

Fig. 2a-d show sample WG/30TEOS/8GA/-25 before and after the burning test. Less than half of the full surface was burnt due to the self-extinguishing nature of the sample (Fig. 2a), and the interior was mostly intact (Fig. 2b, lower image) and protected from exposure to the external flames. Fig. 2c shows a SEM image of the surface located burnt material, with the cellular structure remaining.

At a higher magnification, a granular structure was observed, where the smallest features had a diameter of $c a .10 \mathrm{~nm}$ (Fig. 2d). This granular structure was similar to that of the unburnt material (Fig. 3f). Fig. 2e shows the granular structure isolated/extracted (by centrifugation) from the WG mixture before freezing drying. A network of associated particles developed prior to the solidification (removal of aqueous phase) of the WG mixture. Hence, the structure of the WG cell wall with an internal granular structured network was to some extent determined already during the early formation of the hybrid foams. The "particle" entities in Fig. 2e were larger $(40-50 \mathrm{~nm})$ than the "particles" observed in the burnt material (Fig. 2d), suggesting that the particles in the extracted phase were partially condensed/polymerized silica particles, which during the extensive freeze-drying consolidated into the WG walls as smaller $\mathrm{SiO}_{2}$ particles. Although the fabrication techniques were different, the WG/30TEOS/8GA/-25 foam structure was similar to that of the WG/silica solid films recently reported. ${ }^{23}$ These films showed a clear WG/silica interpenetrating network (IPN) at a TEOS contents of 40 to $60 \%$. The TEOS contents used herein to make the foams were lower than those used to make the solid films, but similar interpenetrating networks also developed in the foams. To further evaluate the IPN uniformity, the fire-tested WG/30TEOS/8GA/-25 sample was heated to $1000{ }^{\circ} \mathrm{C}$ in air. The residual material was white, weak, and "fluffy", as would be expected in a silica network of high porosity, Fig. 2e (inset).

Thermogravimetric analysis on the samples as related to their heat induced degradation was carried out for all samples under oxygen atmosphere (Fig. S1 ESI $\dagger$ ). The on-set temperature of degradation occurred at $c a .230{ }^{\circ} \mathrm{C}$. The maximal mass loss rate decreased with increasing TEOS content in the region from ca. $250{ }^{\circ} \mathrm{C}$ to $550{ }^{\circ} \mathrm{C}$. Even though the experiment was considerably different from the true burning, a distinct difference between the $20 \%$ TEOS and $30 \%$ TEOS sample was observed in the 250 to $320{ }^{\circ} \mathrm{C}$ region. The $30 \%$ sample showed a more gradually declining mass with increasing temperature. This slower mass loss was related to the formation of a larger amount of water phase formed from the partially condensed/polymerized silica particles, which required more time to diffuse from 
(a)

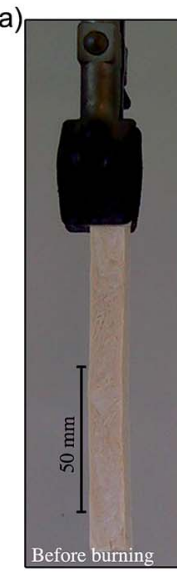

(e)
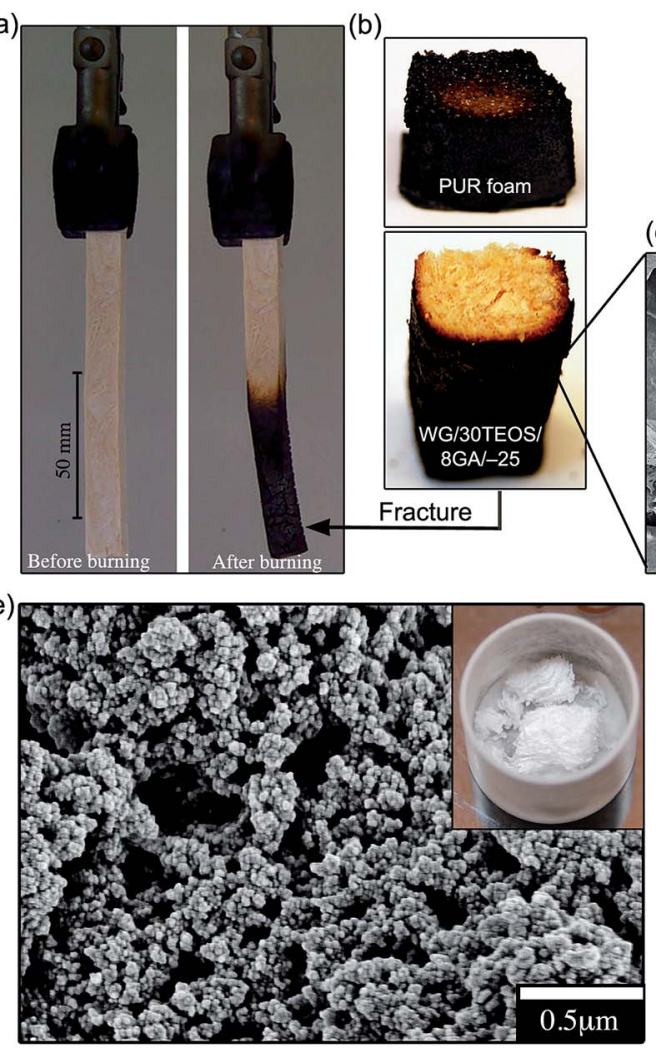

(c)

(d)
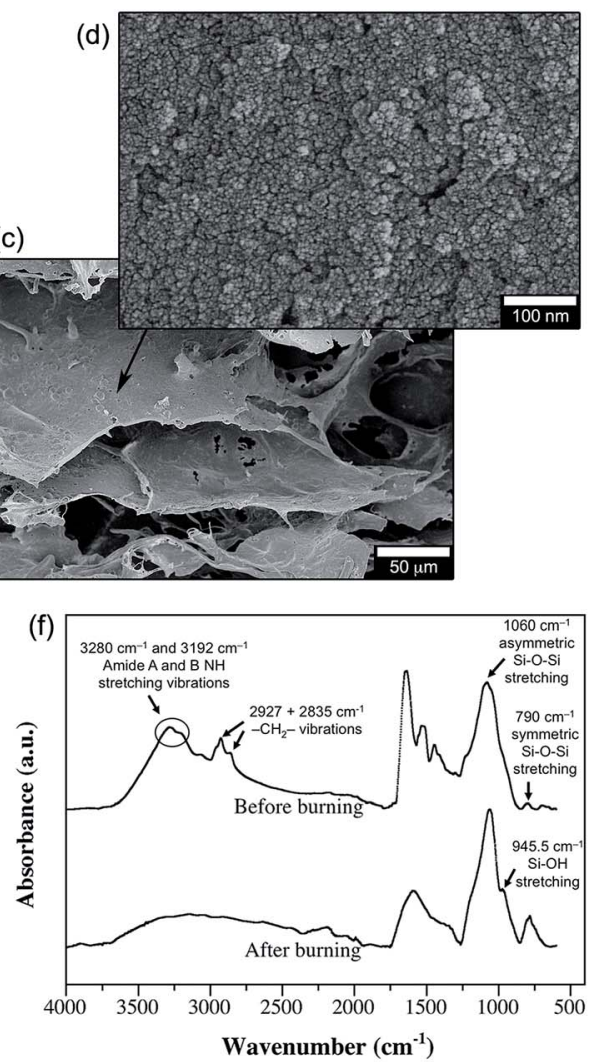

Fig. 2 (a) Image of the WG/30TEOS/8GA/-25 specimen before and after burning, (b) cross-sections of the burnt WG/30TEOS/8GA/-25 foam (lower image) taken at the point of the arrow, and the polyurethane foam after burning (upper image). (c and d) SEM images of the black part of the WG/30TEOS/8GA/-25 foam, (e) SEM image of the silica structure after extraction of the WG component obtained from the mixture before freezing and drying. The inset shows the same structure after complete calcination of the prepared foam, and (f) IR spectra of the WG/30TEOS/ $8 \mathrm{GA} /-25$ foam before and after the UL94 burning test.

the foam walls. Since the foams prepared with $\geq 30 \%$ TEOS exhibited improved flame-retardant properties (according to the UL94 test), it was therefore suggested that the mechanism for the flame-retardant properties was strongly connected with the formation of the silica phase and the dissipation of $\mathrm{H}_{2} \mathrm{O}$ during this phase formation. It is also possible that the formed inorganic silica phase at contents $\geq 30 \%$ to some extent showed improved thermal stability due to hindrance in diffusion of decomposition products, which was recently reported by Chen et $a .^{\mathbf{2 4 , 2 5}}$ The thermogravimetric analysis further confirmed that residual mass after heating to $900{ }^{\circ} \mathrm{C}$ corresponded within $1.9 \pm$ $1.6 \%$ to the calculated content of $\mathrm{SiO}_{2}$, based on the mass of TEOS in the different samples (Table S3, ESI $\dagger$ ). With increasing content of TEOS, the total amount of char was $12.6 \%$ for the $30 \%$ TEOS sample with good self-extinguishing properties (Table $\mathrm{S} 3 \dagger$ ).

To obtain more information about the TEOS products present in the burnt black layers, as well as in the interior of the burnt foams, infrared spectra were recorded. Fig. $2 \mathrm{f}$ shows the IR spectra of WG/30TEOS/8GA/-25 before and after burning. The absence of a clear peak close to $1142 \mathrm{~cm}^{-1}$, corresponding to the stretching of the Si-O-ethyl group, showed that already before burning the TEOS had reacted to form silica, visible as Si-O-Si asymmetric stretching at $1060 \mathrm{~cm}^{-1}$, and silica with residual $\mathrm{OH}$ groups $\left(\mathrm{Si}-\mathrm{OH}\right.$ stretching at $945 \mathrm{~cm}^{-1}$ and $3000-$ $\left.3500 \mathrm{~cm}^{-1}\right){ }^{23}$ The presence of possible ethyl remains in the form of ethanol (from the dissociation of the TEOS precursor) and aliphatic structures related to the proteins, could however be observed as represented by the $-\mathrm{CH}_{2}-$ vibrations at 2927 and $2855 \mathrm{~cm}^{-1}$. These features were completely absent in the charred regions of the foam. The peak due to $\mathrm{Si}-\mathrm{OH}$ stretching at $945 \mathrm{~cm}^{-1}$ in the burnt foam became more distinct as the peak assigned to $\mathrm{Si}-\mathrm{O}-\mathrm{Si}$ asymmetric stretching at $1060 \mathrm{~cm}^{-1}$ narrowed, which is associated with a more condensed silica network structure. ${ }^{26}$ The IR spectrum of the burnt material also showed a prominent peak at $c a .790 \mathrm{~cm}^{-1}$ due to the symmetric stretching of the Si-O-Si network. Apart from the IR vibrations related to the siliconeoxide-based IPN, the amide I and II regions related to the protein structures in the foams ( $c a$. 1450$1750 \mathrm{~cm}^{-1}$ ) showed a less distinct and indiscernible pattern in the case of its degradation products. The typical amide features of the WG in the $3150-3300 \mathrm{~cm}^{-1}$ region was also absent.

XPS was further used to assess the chemical structure of the charred black sections and the intact internal sections of the burnt wheat gluten foam with 30\% TEOS (WG/30TEOS/-25). In order to keep the number of parameters as low as possible to investigate the silica structure in relation to the main WG component, the cross-linker was omitted. The surface analysis 


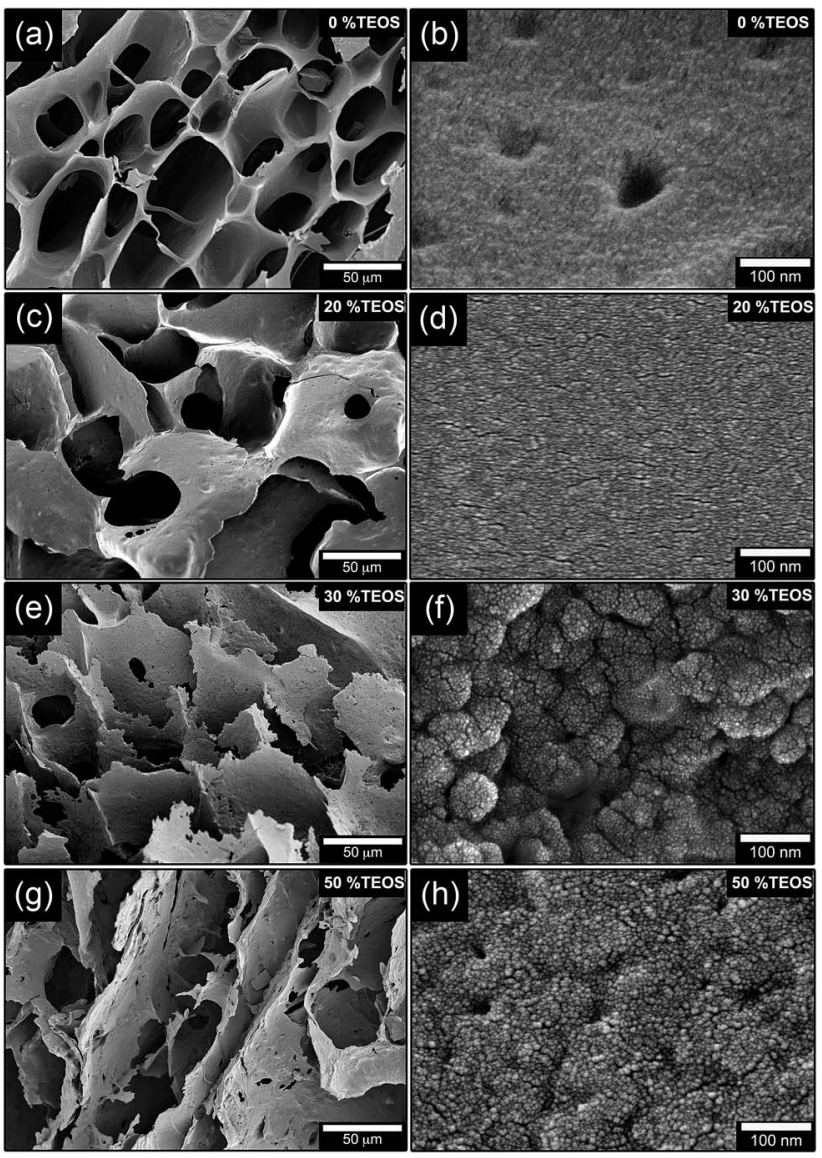

Fig. 3 FE-SEM images of foams frozen at $-25^{\circ} \mathrm{C}$ prepared with (a) 0 , (c) 20, (e) 30 and (g) 50\% TEOS. Images (b), (d), (f), and (h) correspond to magnified areas of, respectively, the $0,20,30$ and $50 \%$ TEOS foams.

showed that the carbon content was $67-68$ at\% in the intact non-carbonized interior and charred black sections of the WG/30TEOS/ -25 materials, see Fig. 2 b. In the WG/ -25 material without silica the carbon content was 77 at\%, because of the absence of "diluting" effect by the $\mathrm{SiO}_{2}$. The main difference at the different sampling sites related to the percentage silicone atoms relative to oxygen, which occurred as $\mathrm{SiO}_{2}$ in both the intact (before burning) and burnt materials, as revealed by the symmetric $\mathrm{Si}(2 \mathrm{p})$ peak located at 103.4-103.6 eV. The unburnt WG/30TEOS/-25 material showed $18.2 \%$ silicone atoms in relation to presence of oxygen, whereas the intact interior of the WG/30TEOS/-25 material revealed a 15.3 at $\%$ of the sample. In the charred exterior of the samples, this value decreased to 10.7 at $\%$. The explanation to the smaller relative amounts of silicone to oxygen, and consequently larger value of oxygen to silicone atoms, was consistent with the formation of a more oxidized structure that formed during the heating and burning of the sample surface. The XPS data also showed that the sulphur $(\mathrm{S}(2 \mathrm{p}))$ initially present in cystine disulphide bonds (163-164 eV) oxidized into sulphate/sulphonate or similar functional groups (168-169 eV) during burning. In all the samples (even the burnt material), nitrogen showed a peak at ca. $400 \mathrm{eV}$, assigned to amide/amine groups. This was in accordance with the IR spectroscopy data of the burnt material, showing that, even though the typical patterns of amides I and II were absent, the material still absorbed IR radiation in this region. The fact that the content of nitrogen was similar in the burnt and pristine foams (6-7 at\%) indicated that there was a fairly large fraction of remaining "protein-like" material in the sampled charred sections. Hence, due to the rapid self-extinguishing of the flame, the burning was not complete in the black surface layers. All XPS measurements were confirmed by 3 measurements on each sample at different positions.

\subsection{Cell structure and cell size distribution}

Fig. 3 shows the cross-sections of all the foams prepared at $-25{ }^{\circ} \mathrm{C}$, in which mainly open cells were observed. The surface morphology characteristics within the specific samples were always the same and suggested a very even phase distribution of the partially condensed/polymerized silica particles, Fig. 3c-h. The foam structures in the samples with $30 \%$ and $50 \%$ TEOS (Fig. 3e and g, respectively) exhibited a fracture surface with a more "glass-like" structure with sharper cell-wall edges, and cell-wall surfaces with a more granular particle-like structure, indicating that the particles were rich in silica (Fig. $3 f$ and $h$ ).

The higher magnifications (the right column, Fig. 3) show that a morphological transition in the material structure occurred between 20 and 30\% TEOS samples, which was synonymous with the transition from a poor to a good flameretardant material. The $20 \%$ TEOS samples showed a uniform, even wall surface with an apparent well distributed silica particle phase embedded in the WG walls (Fig. 3d), whereas the $30 \%$ TEOS showed a surface which seamed to have emanated from a consolidation of a more unevenly blended WG-silica suspension. The observed difference in morphology between the $20 \%$ and $30 \%$ TEOS samples, also displayed in the mechanical characteristics, see Section 3.4.

Fig. 4 shows a comparison of the structures of foams frozen at $-25^{\circ} \mathrm{C}$ and $-196^{\circ} \mathrm{C}$, and the influence of the silica component. The more rapidly formed foams frozen at $-196{ }^{\circ} \mathrm{C}$ had significantly smaller cells and also a more emphasized anisotropic cell structure than the foams frozen at $-25{ }^{\circ} \mathrm{C}$. More magnified images of the cell wall surfaces revealed the same type of graininess in foams prepared with $30 \%$ TEOS and frozen at $-196{ }^{\circ} \mathrm{C}$ (not shown) as in the foams frozen at $-25{ }^{\circ} \mathrm{C}$ (Fig. 3f). Fig. 5 shows the average cell diameters obtained by mercury intrusion porosimetry (MIP) measurements as a function of the TEOS content. The foams frozen at $-196^{\circ} \mathrm{C}$ had a cell diameter in the range of $2-10 \mu \mathrm{m}$, which correlated relatively well with the cell sizes established from manual measurements by SEM (Table 1). However, the foams frozen at $-25^{\circ} \mathrm{C}$ showed smaller cell diameters ranging from $c a .20 \mu \mathrm{m}$ to $60 \mu \mathrm{m}$ as compared to the 40 to $80 \mu \mathrm{m}$ range observed from SEM micrographs (5-50\% TEOS in the foams). The differences were attributed to that the MIP cell sizes are calculated under the assumption that the cells are cylinder-shaped. The true cell shapes were more of elongated cuboidal nature, penetrating the material in the direction of the ice crystal growth, Fig. $4 \mathrm{a}$ and $\mathrm{d}$. The dimensions of the cells were therefore determined as the 

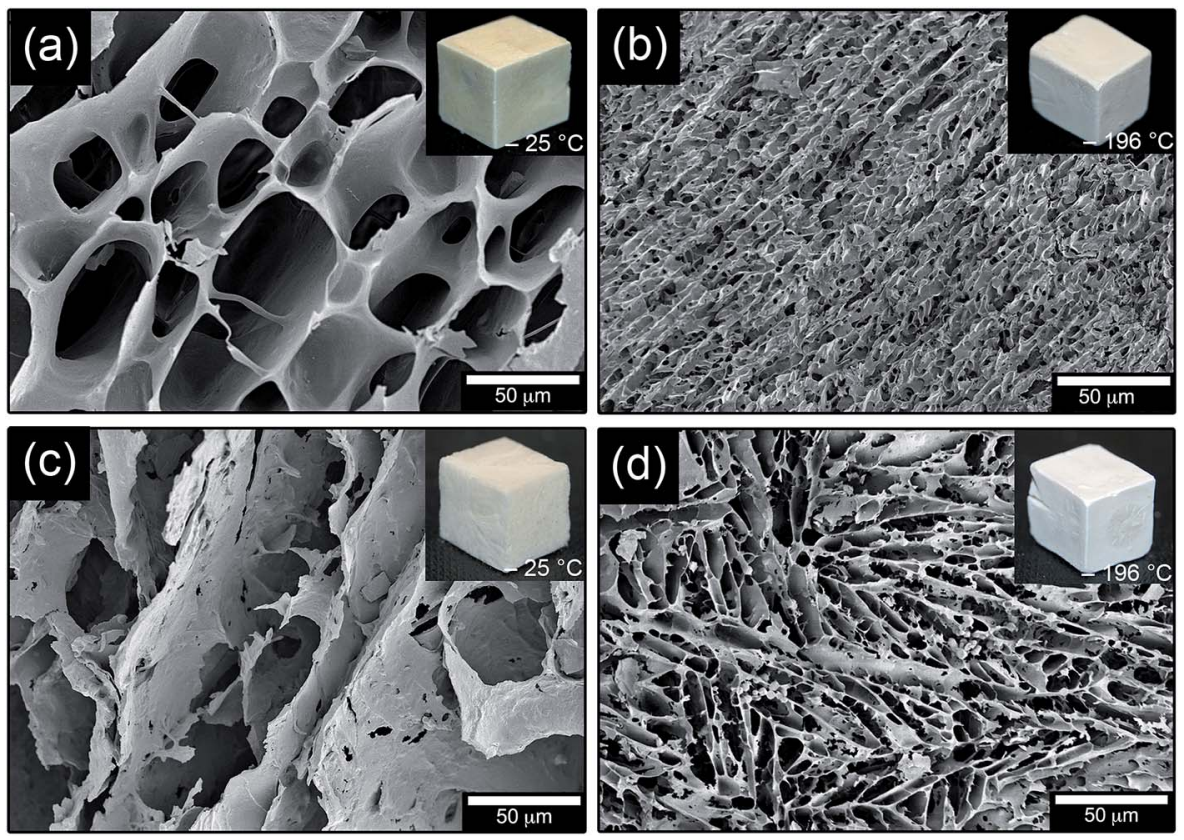

Fig. 4 FE-SEM images of foams frozen at $-25^{\circ} \mathrm{C}$ prepared with (a) 0 and (c) $50 \%$ TEOS. Foams frozen at $-196{ }^{\circ} \mathrm{C}$ prepared with 0 and $50 \%$ TEOS are shown in (b) and (d)

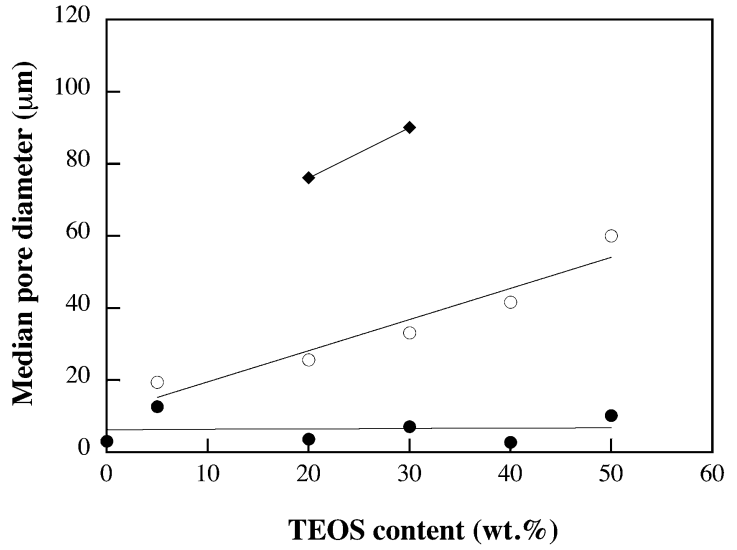

Fig. 5 Median pore diameter as a function of TEOS content; foams frozen at $-25{ }^{\circ} \mathrm{C}$ without $(O)$ and with $(\diamond)$ crosslinker (8\% glutaraldehyde). Also shown are foams frozen at $-196^{\circ} \mathrm{C}(\mathbf{O})$.

largest diameter within the cell, and if only two opposite walls were identified (elongated cells). In addition, the cells occasionally showed open passes in the interconnecting walls, i.e. between the cells, which may have influence on the MIP measurements. The same observation was made for the silica free foam (WG/-25), which had a cell size of $c a .80 \mu \mathrm{m}$ (not shown) according to MIP measurements, whereas the SEM micrographs (Fig. 4a) resulted in a more true average cell size of ca. $50 \mu \mathrm{m}$ (Table 1) based on minimum of 50 measurements.

The silica-free foam frozen at $-25^{\circ} \mathrm{C}$ was brown whereas the foam frozen in liquid nitrogen appeared more bright and became whiter as the amount of silica was increased (Fig. 4). The foams had the same colour all over the surface and inside (not shown), indicating that the silica was uniformly dispersed in the foam. Accordingly, the sizes of the cells and the content of silica determined the colour of the foams. This uniformity/ homogenity of the silica phase inside the foams stemmed from the in situ polymerization/condensation of the silanol functional silica precursor, which was completely soluble in the denatured wheat gluten suspensions due to complete hydrolysis before addition.

As shown in Table 1, there was no specific trend in foam density values with changing silica (TEOS) content. The densities were determined from the mass and the volume of the dry foams and varied between 127 and $166 \mathrm{~kg} \mathrm{~m}^{-3}$. The values depended primarily on the water content in the mixture before the freeze-drying, since the water constituted the major volume of the mixture and was eliminated as frozen crystals in the sublimation process. The amount of air that was trapped during mixing only had a minor influence on the densities of the foams because the system was always given time to settle ( $>15 \mathrm{~min})$ before the freezing operation. Assuming a density of $2200 \mathrm{~kg}$ $\mathrm{m}^{-3}$ for fused $\mathrm{SiO}_{2}$ and $1300 \mathrm{~kg} \mathrm{~m}^{-3}$ for WG, ${ }^{27}$ the porosity of the foams were calculated to be within the range 87 to $91 \mathrm{vol} \%$.

\subsection{Mechanical properties}

Examples of compressive stress-strain curves are shown in Fig. 6a. In general, the stress-strain curve consisted of three characteristic regions, starting with an elastic linear region at low stresses and strains followed by a plateau caused by cell collapse. The third region occurred when the cell walls had collapsed and was characterized by a rapidly rising stress accompanied by very little further deformation of the solid material. Fig. 6a shows that the three regions were more readily 

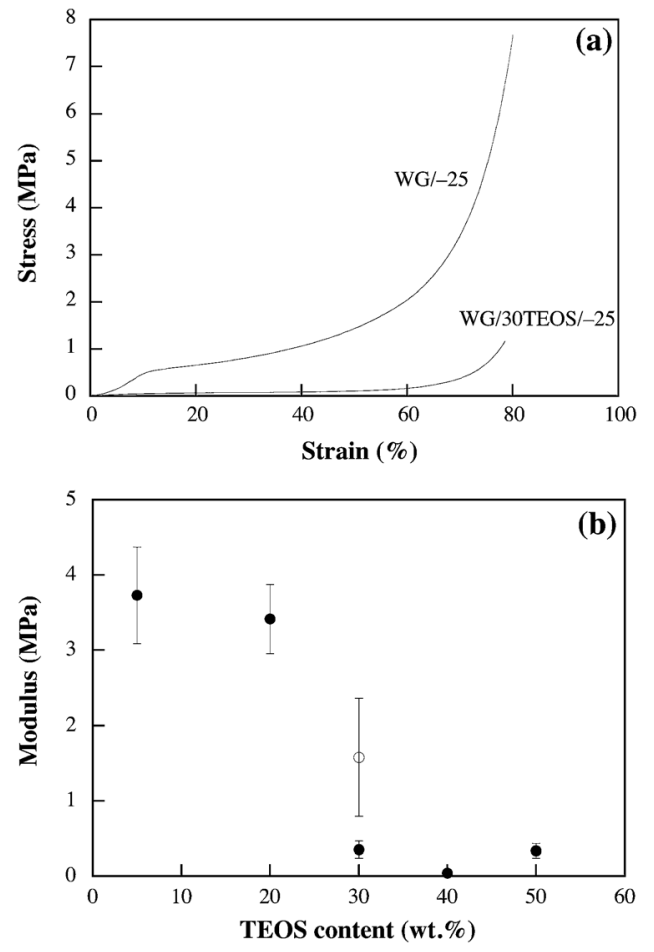

Fig. 6 (a) Stress-strain curves of WG/ -25 and WG/30TEOS/-25, (b) modulus of foams prepared at $-25^{\circ} \mathrm{C}$ as a function of silica/TEOS content ( ) and cross-linked with $8 \%$ glutaraldehyde $(\bigcirc)$.

resolved in the stiffer and stronger foam (WG/-25). The modulus of the foams was obtained as the maximum slope of the stress-strain curve in the initial linear region, i.e. below a strain of typically $10 \%$. The modulus of WG/ -25 was $6.9 \pm 0.5$ $\mathrm{MPa}$, and decreased with increasing silica/TEOS content (Fig. 6b). This reflected a decrease in the cell wall strength for the $-25{ }^{\circ} \mathrm{C}$ foams due to the fragility of the silica component. The cell walls also became thinner with increasing silica content. For instance, the average cell wall thickness of WG/-25 foam was $4 \mu \mathrm{m}$, by adding TEOS of $30 \%$, average cell wall thickness became $1 \mu \mathrm{m}$. The large decrease in modulus between 20 and $30 \%$ TEOS for the foams frozen at $-25^{\circ} \mathrm{C}$ correlated with the improvement in flame-retardency, which was also seen for the liquid $\mathrm{N}_{2}$-frozen foams. This suggests that a more complete protective silica network was formed using $\geq 30 \%$ TEOS, but that this yielded a weaker foam.
In order to improve the strength of the foam, the foam produced with the homogenizer was degassed in vacuum, so that the largest cells containing air were removed, or the protein was cross-linked with glutaraldehyde (GA).

A combination of the two approaches had a significant positive effect, and the foam produced at $-25{ }^{\circ} \mathrm{C}$ with $30 \%$ TEOS, cross-linked with $8 \% \mathrm{GA}$ and vacuum-treated, showed a modulus which was 3.6 times higher than that of the same sample without the cross-linker (Fig. 6b). This material showed inherent mechanical properties that allowed it to be handled as traditional foam for heat insulating applications, i.e. PUR.

\subsection{Thermal conductivity}

Table 2 shows the thermal properties of the selection of foams that could be properly cut for evaluation of their thermal properties. The specific heat capacity values were between 1.2 and $1.5 \mathrm{~J}\left(\mathrm{~g}^{\circ} \mathrm{C}\right)^{-1}$, which are similar to the values reported in the literature for polystyrene and polyurethane foams (1.3 and $\left.1.5 \mathrm{~J}\left(\mathrm{~g}^{\circ} \mathrm{C}\right)^{-1}\right) .^{28}$

The thermal diffusivity values obtained for the three foams in Table 2 were $0.2-0.3 \mathrm{~mm}^{2} \mathrm{~s}^{-1}$. The thermal conductivity, calculated by eqn (3) (Experimental, Section 2.5), was 0.04-0.06 $\mathrm{W}\left(\mathrm{m}{ }^{\circ} \mathrm{C}\right)^{-1}$, indicating that the thermal insulation was comparable to, or slightly higher than, those of conventional high-insulation petroleum-based closed-cell foams such as polyethylene $\left(0.03 \mathrm{~W}\left(\mathrm{~m}^{\circ} \mathrm{C}\right)^{-1}\right),{ }^{29}$ polyurethane $(0.02-0.03 \mathrm{~W}$ $\left.\left(\mathrm{m}{ }^{\circ} \mathrm{C}\right)^{-1}\right)^{30}$ and polystyrene $\left(0.02-0.04 \mathrm{~W}\left(\mathrm{~m}^{\circ} \mathrm{C}\right)^{-1}\right) .^{28}$ The thermal conductivity was also in the same range as that of perlite $\left(0.03-0.05 \mathrm{~W}\left(\mathrm{~m}^{\circ} \mathrm{C}\right)^{-1}\right),{ }^{31}$ glass fibre and rock wool $(0.04-$ $\left.0.05 \mathrm{~W}\left(\mathrm{~m}^{\circ} \mathrm{C}\right)^{-1}\right),{ }^{32}$ cellulose-based ecofiber $\left(0.04 \mathrm{~W}\left(\mathrm{~m}^{\circ} \mathrm{C}\right)^{-1}\right)$ and better than wood wool $\left(0.09 \mathrm{~W}\left(\mathrm{~m}^{\circ} \mathrm{C}\right)^{-1}\right)$.

\subsection{Protein structure}

Wheat gluten contains $c a .50 \%$ glutenin and $50 \%$ gliadin, which are the main part of polymeric and monomeric proteins, respectively. The representation of these can be determined from their elution times (polymeric proteins are eluted early) by SE-HPLC experiments. ${ }^{25}$ The thermal treatment at high $\mathrm{pH}$ during the foam preparation led to protein denaturation (destruction of the initial protein 3-dimensional structure), with a subsequent polymerisation of the polymeric and monomeric proteins via disulfide recombination from intra- to intermolecular crosslinks and thiols forming intermolecular disulfide crosslinks. ${ }^{33}$ Since the final cell structure and foam properties

Table 2 Thermal properties at $30^{\circ} \mathrm{C}$

\begin{tabular}{|c|c|c|c|c|}
\hline Sample & $\rho^{a}\left(\mathrm{~kg} \mathrm{~m}^{-3}\right)$ & $C_{\mathrm{p}}^{b}\left(\mathrm{~J}\left(\mathrm{~g}^{-1}{ }^{\circ} \mathrm{C}\right)\right)$ & $D^{c}\left(\mathrm{~mm}^{2} \mathrm{~s}^{-1}\right)$ & $\lambda^{d}\left(\mathrm{~W}\left(\mathrm{~m}^{-1}{ }^{\circ} \mathrm{C}\right)\right)$ \\
\hline WG/-25 & $130.40 \pm 7.60$ & $1.36 \pm 0.04$ & $0.22 \pm 0.01$ & $0.039 \pm 0.003$ \\
\hline WG/20TEOS/-25 & $162.60 \pm 2.50$ & $1.20 \pm 0.05$ & $0.29 \pm 0.01$ & $0.057 \pm 0.003$ \\
\hline
\end{tabular}

${ }^{a}$ Foam density shown as average value with standard deviations based on five replicates. ${ }^{b}$ Specific heat capacity obtained from a second heating at a heating rate of $1^{\circ} \mathrm{C} \mathrm{min}{ }^{-1}$. Average values and standard deviations are based on two values from each heating rate. ${ }^{c}$ Thermal diffusivity shown as average value with standard deviations based on 4 to 15 data points. ${ }^{d}$ Thermal conductivity calculated with eqn (3) standard deviations are based on maximum and minimum values. 
depended on the protein structure, Fig. 7a illustrates the foam preparation and how the protein solubility was evaluated by protein extraction. The amount of the proteins that are only loosely bonded within the structures through secondary bonds can be determined by first treating the material with sodiumdodecyl sulfate (SDS), see Ext. 1 in Fig. 7a. SDS is known to break secondary bonds. ${ }^{\mathbf{1 1}}$ Further, by sonicating the materials for different times (Exts. 2 and 3), the disulfide bonds break and it is also possible to quantify the larger sized protein molecules that were initially tied together with disulfide crosslinks. ${ }^{11}$ Even though not all proteins are extracted, since the amount and size of the proteins extracted by sonication depends on the size and complexity of the protein polymer, ${ }^{34}$ the method provides information on the degree of polymerization, i.e. structural integrity of the materials.

The total protein solubility (Total Ext.), which is known to decrease with increasing protein polymerization, ${ }^{34}$ was higher in the foam produced by the rapid liquid $\mathrm{N}_{2}$-cooling (WG/-196) than in the more slowly cooled foam (WG/-25) (compare the blue and red columns in Fig. 7b). This cooling-rate dependence indicated that the polymerization of the WG polymer continued after the $90{ }^{\circ} \mathrm{C}$ heating and mixing with hydrolysed TEOS, and that a slower freezing allowed for a more cross-linked structure during its consolidation into a solid material. Since less than $50 \%$ of the proteins were extracted with SDS (Ext. 1), some gliadins must also have been crosslinked into the WG foams. Previously, WG foams showed a significantly higher protein solubility during the SDS treatment, indicating a lower degree of crosslinking. ${ }^{7,20}$ This was explained by the higher denaturation temperature used $\left(90^{\circ} \mathrm{C}\right)$, compared to that used in the previous study $\left(75^{\circ} \mathrm{C}\right)$. To conclude, the protein polymerization was highest for the more slowly cooled foams $\left(-25^{\circ} \mathrm{C}\right)$, which also explained why these foams were tougher than the liquidnitrogen cooled foams.

Considering the entire TEOS/silica range, the solubility of the foams frozen at $-25{ }^{\circ} \mathrm{C}$ showed a decrease with increasing silica content for the different extraction steps (Fig. 7b). However, the presence of a small fraction of silica (5-20\% TEOS) increased the protein solubility (see the 2 first grey columns from the left for each extraction step, Fig. 7b). The trend was also present in the materials prepared at $-196^{\circ} \mathrm{C}$. From the two sets of columns to the far right (Mon and Pol) it is also demonstrated that the relative amounts of extracted monomeric to polymer entities increased with increasing silica content. This shows that the presence of an interpenetrating silica network restricted the possibilities to extract the larger polymerized proteins, which also was consistent with a lower degree of protein polymerization for larger amounts of TEOS (Fig. 7b). ${ }^{28}$

For example, the amount of protein extracted from the foam made with $80 \%$ TEOS was $4 \%$, whereas the amount of protein extracted from the silica-free foam was $69 \%$. The $80 \%$ TEOS content was here added, which was a very fragile foam, to confirm these phenomena. The large decrease in total protein solubility between 20 and 30\% TEOS is noteworthy (Fig. 7b). This abrupt change in protein solubility occurred in the TEOS range where a drastic improvement in the flame-retardant properties was observed and where the modulus decreased significantly. Fig. 7c shows the effects of glutaraldehyde crosslinking on the protein solubility. The total solubility decreased with increasing GA content and the solubility of both
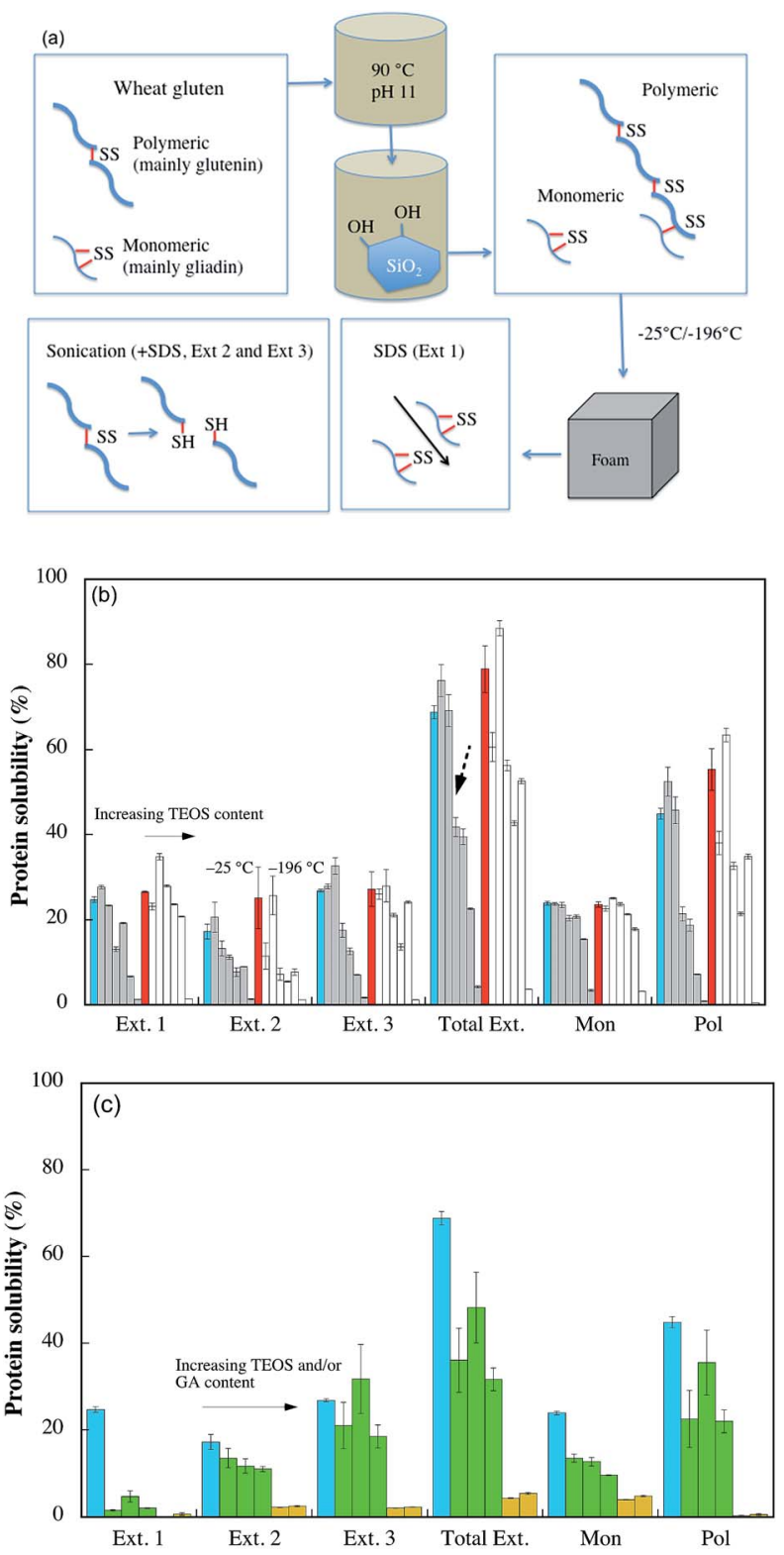

Fig. 7 Protein solubility. (a) Illustration of the protein structure present before and during/after foam preparation, and what structures are determined by SE-HPLC. (b) The grey and white columns represent the WG/silica foams frozen at $-25{ }^{\circ} \mathrm{C}$ or $-196{ }^{\circ} \mathrm{C}$, respectively. The columns represent, from left to right: WG with 0 (blue $=W G /-25$, red $=W G /-196), 5,20,30,40,50$ and 80\% TEOS, (c) From left to right the columns represent WG/-25, WG/10TEOS/8GA/-25, WG/20TEOS/ 8GA/-25, WG/30TEOS/8GA/-25, WG/20TEOS/16 GA/-25 and WG/ 30TEOS/16 GA/-25, respectively. Ext. 1 refers to the first extraction with SDS, Ext. 2 refers to extraction with SDS and a 30 s sonication, and Ext. 3 refers to extraction with SDS and repeated sonication $(30+60 \mathrm{~s})$. Total Ext. refers to Ext. $1+$ Ext. 2 + Ext. 3. Mon and Pol refer to the total monomeric and polymeric protein extractions from the three extraction steps. The broken arrow in Fig. $7 \mathrm{~b}$ highlights the large decrease in total protein solubility between 20 and 30\% TEOS. 
monomeric and polymeric proteins was lower in the presence of GA. At a level of $16 \%$ GA, no polymeric proteins were extracted from the foams. The monomeric protein solubility of the foams prepared with $16 \%$ GA was low also after the sonication treatment, indicating that GA effectively worked as a cross-linker for the materials.

Fig. 8 shows the amide I peak, whose shape depends on the polymer backbone conformation (the secondary structure of the protein). ${ }^{23}$ It should be noted that silica had no absorption in the amide I region. The bands at 1658, 1651 and $1644 \mathrm{~cm}^{-1}$ are assigned, respectively, to the presence of $\alpha$-helices, $\alpha$-helices/ random coils and disordered material, whereas the region $1635-1618 \mathrm{~cm}^{-1}$ is attributed to the presence of $\beta$-sheets, which indicates an aggregated/polymerized protein. ${ }^{35}$ The IR spectra of the foams frozen at $-25{ }^{\circ} \mathrm{C}$, prepared with 0 and $30 \%$ TEOS, showed a more intense $\beta$-sheet region than the corresponding foams frozen at $-196{ }^{\circ} \mathrm{C}$, indicating a greater polymerization in the former foams, as was confirmed in the previous sections. This is in accordance with the protein solubility data that showed that most of the foams produced at $-25{ }^{\circ} \mathrm{C}$ were more polymerized than the quenched foams.

The shape of the curve of the foam cross-linked with GA (WG/30TEOS/8GA/-25) was similar to that of the GA-free foam (WG/30TEOS/-25), indicating that the secondary protein structure was not changed in the presence of GA. There was a slight decrease in the intensity in the $\beta$-sheet region from 0 to $50 \%$ TEOS (not shown), indicating a lower degree of polymerization with increasing silica content. Surprisingly, the IR spectra of the foams produced with $80 \%$ TEOS at $-25{ }^{\circ} \mathrm{C}$ and $-196{ }^{\circ} \mathrm{C}$, were very different from the spectra obtained for the other foams (only the WG/80TEOS/-25 curve is shown in Fig. 8). They had a maximum close to $1651 \mathrm{~cm}^{-1}$, indicating a greater presence of $\alpha$-helix/random coils and disordered structures and less $\beta$-sheets. To conclude, based on the IR spectroscopy data, which was in line with SE-HPLC data, the protein polymerization/aggregation decreased with increasing silica content yielding at $80 \%$ TEOS a protein with very little aggregation. It is

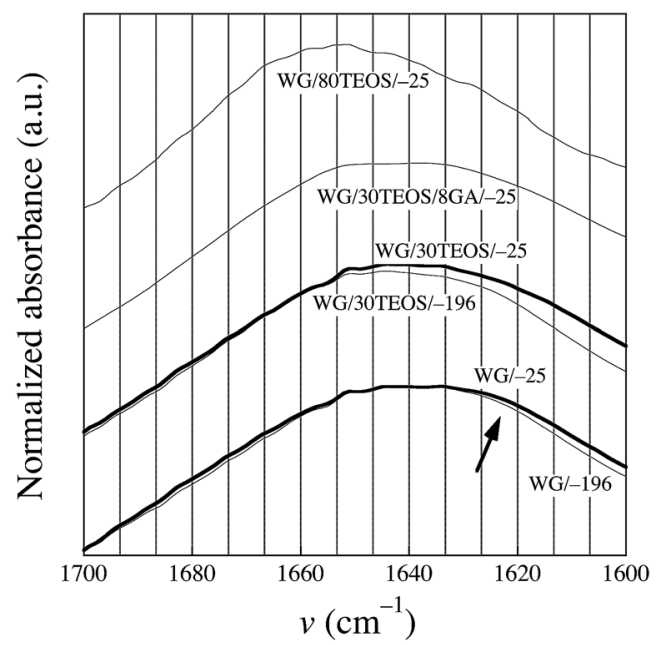

Fig. 8 Infrared spectra of the different foams. The arrow points to the region associated with the presence of $\beta$-sheets. likely that the silica surface, with its hydroxyl groups, constrained the protein molecules to such an extent that polymerization was hindered. The same interactions, together with the encasing effect of silica, was probably the reason for the low protein solubility of the foams made with $80 \%$ TEOS.

\subsection{Moisture uptake}

The moisture content at $50 \pm 2 \% \mathrm{RH}$ of the different foams ranged from 2 to $6 \mathrm{wt} \%$ (Fig. 9). Considering the whole range in TEOS/silica content, the moisture content decreased with increasing silica content.

Hence, the fire retarding effect was not associated with silicaadsorbed water and the moisture uptake was lower for higher contents of silica. At low $0-30 \%$ TEOS contents $\left(-25{ }^{\circ} \mathrm{C}\right.$ system $)$, the moisture uptake was insensitive to the silica content. An interesting aspect of these observations is that if the silica phase was present as a dispersed phase of high surface area particles, it should be susceptible to significant water uptake. The results in Fig. 9 were therefore interpreted as related to a bulk behaviour of the silica phase, which is in contrast to the behaviour of a dispersed particle phase. An extrapolation of the graph to $100 \%$ silica shows in fact a water adsorption in the vicinity of 0 wt $\%$, which is synonymous with a very small amount of surface adsorbed water on the silica. A linear correlation from maximum to minimum water uptake was however not observed. This indicated that uptake of moisture at low silica contents may have been associated hydroxyl groups on the silica surface and the WG, whereas at higher silica contents the bulk properties of the silica dominated. Fig. 9 also shows that the liquid $\mathrm{N}_{2}$-frozen foams underwent a decrease in moisture content similar to that observed for the $-25{ }^{\circ} \mathrm{C}$ foams. The foams based on $8 \%$ GA had, in general, a lower moisture content than the GA-free foams, which was further reduced for the foams produced with 16\% GA, see inset (Fig. 9). To conclude, since the most flame-retardant foams contained the

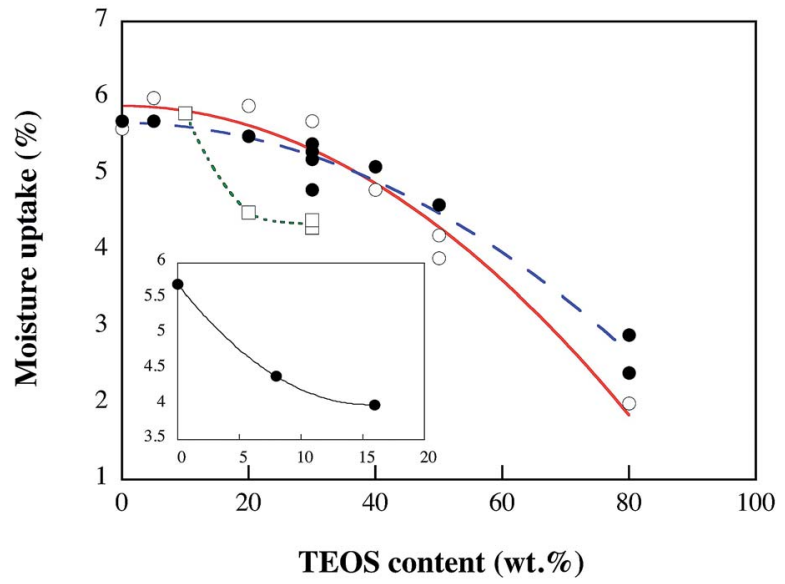

Fig. 9 Moisture content as a function of silica (TEOS) content; foams prepared at $-25^{\circ} \mathrm{C}(\mathrm{O})$, at $-196{ }^{\circ} \mathrm{C}(\mathbf{O})$, cross-linked with $8 \% \mathrm{GA}(\boldsymbol{\square})$ and $16 \%$ GA (inset curve). The overall standard deviation was $\pm 9 \%$ of the value, as estimated from 60 measurements on WG and silica-WG foams. 
same amount, or less of moisture than the non-flame retardant, the moisture content $(2-6 \mathrm{wt} \%)$ was not responsible for the flame-retardancy. However, unreacted $\mathrm{Si}-\mathrm{OH}$ groups may during "complete" combustion turn into $\mathrm{SiO}_{2}$ with water release, a process that is expected to contribute to an improved fire resistance.

\section{Conclusions}

Flame-retardant wheat gluten foams with an integrated partially condensed silica phase from hydrolysed tetraethyl orthosilicate (TEOS) is demonstrated as a sustainable alternative to petroleum based foam materials. The integrated phase was polymerized in situ during the consolidation of the materials in the foaming procedure, which was controlled to yield porosities in the range of $87-91 \%$. The cell structure of the prepared foams was varied by adjusting the freezing conditions of the aqueous suspensions of wheat gluten (WG) and tetraethyl orthosilicate (TEOS). This resulted in uniform cell sizes from 2 to $80 \mu \mathrm{m}$, which depended on the formation of differently sized ice crystals that were removed during the lyophilisation. By increasing the TEOS content from 20 to $30 \%$, more brittle foams formed, suggesting that a percolation of the silica phase had occurred. The flame-retardant foam behaviour occured with $20 \%$ TEOS when a glutaraldehyde cross-linker was used to reinforce and compensate for the brittleness of the WG materials with higher contents of silica ( $\geq 30 \%$ TEOS). The intimately mixed twocomponent silica/WG structure yielded a complex relationship between the silica content and the protein solubility/conformational molecular structure. The protein polymerization decreased with increasing silica content, leading to an increase in protein solubility. However, at high silica contents $(80 \%$ TEOS), the encasing effect of the silica, and probably also the hydrogen bonding between WG and silica, dominated and led to very low protein solubility. It was also clear that the slower freezing rate obtained by freezing at $-25{ }^{\circ} \mathrm{C}$ allowed for a more pronounced WG polymerization in the cell walls, since the solubility of these materials were inferior to the solubility of the materials frozen in liquid nitrogen $\left(-196^{\circ} \mathrm{C}\right)$.

Overall, it was concluded that the presence of silica, the silica precursor and the possible additional condensation of the silica precursor during burning (yielding water) significantly increased the flame resistance of the hybrid foams compared to the silica-free WG foams. Possibly, the silica, together with the char, provided a sufficient capping of the internal organic phase, leading to the rapid extinguishing of the fire just below the surface (see Fig. 2b, lower image).

\section{Acknowledgements}

This work was financed by the Swedish Research Council Formas (no. 243-2011-1436), and the governmental research program Trees and Crops for the Future (TC4F). Maria Luisa Prieto-Linde at the Swedish University of Agricultural Sciences is thanked for the SE-HPLC experiments. The infrared camera (FLIR E-30) used for the thermographic analysis was provided by Elfa Disctrilec.

\section{References}

1 R. H. Kramer, M. Zammarano, G. T. Linteris, U. W. Gedde and J. W. Gilman, Polym. Degrad. Stab., 2010, 95, 1115-1122.

2 X. C. Bian, J. H. Tang, Z. M. Li, Z. Y. Lu and A. Lu, J. Appl. Polym. Sci., 2007, 104, 3347-3355.

3 I. Kim, J. T. Ahn, C. S. Ha, C. S. Yang and I. Park, Polymer, 2003, 44, 3417-3428.

4 R. Zhang, J. Feng, X. Cheng, L. Gong, Y. Li and H. Zhang, Energ Build, 2014, 81, 262-267.

5 C. J. Weber, V. Haugaard, R. Festersen and G. Bertelsen, Food Addit. Contam., 2002, 19, 172-177.

6 I. Buresova and L. Hrivna, Appl. Energy, 2011, 88, 1205-1210.

7 T. O. Blomfeldt, R. Kuktaite, E. Johansson and M. S. Hedenqvist, Biomacromolecules, 2011, 12, 1707-1715.

8 R. Kuktaite, H. Larsson and E. Johansson, J. Cereal Sci., 2004, 40, 31-39.

9 J. P. Lens, L. A. de Graaf, W. M. Stevels, C. H. J. T. Dietz, K. C. S. Verhelst, J. M. Vereijken and P. Kolster, Ind. Crops Prod., 2003, 17, 119-130.

10 C. J. R. Verbeek and L. E. van den Berg, Macromol. Mater. Eng., 2010, 295, 10-21.

11 T. O. J. Blomfeldt, R. T. Olsson, M. Menon, D. Plackett, E. Johansson and M. S. Hedenqvist, Macromol. Mater. Eng., 2010, 295, 796-801.

12 T. O. J. Blomfeldt, F. Nilsson, T. Holgate, J. X. Xu, E. Johansson and M. S. Hedenqvist, ACS Appl. Mater. Interfaces, 2012, 4, 1629-1635.

13 M. Gallstedt, A. Mattozzi, E. Johansson and M. S. Hedenqvist, Biomacromolecules, 2004, 5, 2020-2028.

14 H. B. Chen, Y. Z. Wang and D. A. Schiraldi, Eur. Polym. J., 2013, 49, 3387-3391.

15 H. Y. Fan, A. Tekeei, G. J. Suppes and F. H. Hsieh, Int. J. Polym. Sci., 2012, Article ID 474803, 1-8.

16 S. Farris, L. Introzzi, J. M. Fuentes-Alventosa, N. Santo, R. Rocca and L. Piergiovanni, J. Agric. Food Chem., 2012, 60, 782-790.

17 P. A. Webb, C. Orr and R. W. Camp, Analytical methods in fine particle technology, Micromeritics Publishers, Norcross, 1997.

18 R. D. Cowan, J. Appl. Phys., 1963, 34, 926-927.

19 O. Almanza, M. A. Rodriguez-Perez and J. A. de Saja, Polym. Int., 2004, 53, 2038-2044.

20 T. O. J. Blomfeldt, R. Kuktaite, T. S. Plivelic, F. Rasheed, E. Johansson and M. S. Hedenquist, RSC Adv., 2012, 2, 6617-6627.

21 W. Newson, R. Kuktaite, M. Hedenqvist, M. Gallstedt and E. Johansson, J. Am. Oil Chem. Soc., 2013, 90, 1229-1237.

22 J. Guemez, C. Fiolhais and M. Fiolhais, Eur. J. Phys., 2007, 28, 1199-1205.

23 H. Ture, T. O. J. Blomfeldt, M. Gallstedt, M. S. Hedenqvist and S. Farris, Macromol. Chem. Phys., 2013, 214, 1131-1139.

24 H. B. Chen, Y. Z. Wang, M. Sanchez-Soto and D. A. Schiraldi, Polymer, 2012, 53, 5825-5831.

25 H. B. Chen, B. S. Chiou, Y. Z. Wang and D. A. Schiraldi, ACS Appl. Mater. Interfaces, 2013, 5, 1715-1721. 
26 R. T. Olsson, M. S. Hedenqvist, V. Ström, J. Deng, S. J. Savage and U. W. Gedde, Polym. Eng. Sci., 2011, 51, 862-874.

27 C. Wretfors, S. W. Cho, R. Kuktaite, M. S. Hedenqvist, S. Marttila, S. Nimmermark and E. Johansson, J. Mater. Sci., 2010, 45, 4196-4205.

28 S. A. Al-Ajlan, Appl. Therm. Eng., 2006, 26, 2184-2191.

29 T. F. Luo and G. Chen, Phys. Chem. Chem. Phys., 2013, 15, 3389-3412.

30 A. Prociak, J. Pielichowski and T. Sterzynski, Polym. Test., 2000, 19, 705-712.

31 V. Vaou and D. Panias, Miner. Eng., 2010, 23, 1146-1151.
32 W. J. Batty, P. W. Ocallaghan and S. D. Probert, Appl. Energy, 1981, 9, 55-76.

33 F. Rasheed, W. R. Newson, T. S. Plivelic, R. Kuktaite, M. S. Hedenqvist, M. Gallstedt and E. Johansson, RSC Adv., 2014, 4, 2051-2060.

34 E. Johansson, A. H. Malik, A. Hussain, F. Rasheed, W. R. Newson, T. Plivelic, M. S. Hedenqvist, M. Gällstedt and R. Kuktaite, Cereal Chem., 2013, 90, 367-375.

35 S. W. Cho, M. Gallstedt, E. Johansson and M. S. Hedenqvist, Int. J. Biol. Macromol., 2011, 48, 146-152. 